\title{
Understanding the Social Perceptions of Male Saudi Nationals: A Glimpse Into Gender Inequality in the Kingdom of Saudi Arabia
}

\author{
Ali S. Alharethi (Corresponding Author) \\ Lecturer in Human Resource Management, College of Administrative Sciences, Najran \\ University, Kingdom of Saudi Arabia \\ PO box 1988, Najran University, Saudi Arabia \\ Tel: 966-599-315-553_Ｅ-mail: asalharethi@nu.edu.sa
}

Received: February 6, 2019 Accepted: March 16, 2019 Published: March 19, 2019

doi: 10.5296/hrr.v3i1.41326 URL: https://doi.org/10.5296/hrr.v3i1.14326

\begin{abstract}
Saudi Arabia is in the limelight with relation to gender equality throughout the globe. It is said that they exist a shift in the way in which KSA is attempting to alter its society. It is suggested that this is pushed on by globalization, modernization and westernization. One factor that the rest of the globe is focused on relates to the way in which Saudi women viewed treated. This has resulted in drastic changes in policies for women in Saudi Arabia due to both internal and external forces. Saudi Arabia is secretive with relation to the way it conducts its internal policies. With the large number of Saudi students who are studying abroad there is a suggestion this can aid in tackling gender equality issues within Saudi Arabia. This study looks at whether Saudi male student's opinions have changed due to the exposure of other societies and in particular with that of the UK. It is concluded that Saudi male students are in fact altering their perceptions and that exposure to new social environments are pushing these changes in thoughts. Although small in size, the participants of the study support this notion. Ultimately, further analysis is required so as to promote reliability and validity but these results seem somewhat promising to Saudi women.
\end{abstract}

Keywords: Gender, Culture, Religion, Women, Equality, Saudi Arabia

\section{Introduction}

Recent history has shown that within the West there has been a gradual but empowering debate and view of women. The subject of gender inequality within the workplace has also developed a significant understanding towards women in the workplace. Currently we are 
still faced with challenges and barriers that women must deal with within the West. The literature that exists in trying to give insight and context to gender equality is plentiful and diverse. Even though policies and opinion support this movement whereby women are demanding an equal footing compared to their male counterparts (Walby, 2004).

Women in the Muslim developing world are to trying and achieve the same level of equality that can be seen throughout the West. The role of women within the West is somewhat different to that of Saudi Arabian women. Saudi women have a different set of challenges that they must deal with in order to challenge the male dominated labour force (Omair, 2008). The reason for these challenges has been widely debated but environmental forces that can exist with women in the Muslim world are drastically different to other regions around the globe. These forces could relate to social structure, culture, customs and religion. Some countries within the Muslim world have seen a significant change in attitudes for women within society and the workplace (Metcalfe, 2008).

One nation which has seen a significantly lower level of development for gender equality is that of the Kingdom of Saudi Arabia (KSA). This slow movement in attitudes is suggested to be due to cultural and religious forces. It has been somewhat neglected with relation to studies within the KSA borders. Two examples of how there exists a stunt in the growth of woman's rights can be seen by the way in which women are forbidden to drive. Secondly, is that in 2012 Saudi Arabia changed its policy so as to allow women to compete for the first time in the Olympics. Furthermore, Al-Rasheed (2010, p. 268) additionally goes on to suggest "For a very long time women have been a silent minority in Saudi Arabia, although numerically they may outnumber men".

In modern day Saudi Arabia, women's roles are changing at a rapid pace for KSA. Whilst other countries in recent years have seen a steady curve, Saudi Arabia's curve is somewhat more extreme. Metcalfe (2008) defines this more specifically to that of three factors which is that of globalization, westernization and modernization. With this movement there exists a significantly low-level of insight as to how the Saudi Arabian consciousness is viewing this change. Furthermore, this male driven country has seen an explosion in the young male adult population who are becoming increasingly Western educated. It is estimated that 130,397 Saudis are studying aboard and at that $25 \%$ of this are female students (Thomas, 2012). These same individuals will ultimately be absorbed back into the skilled labour market in KSA. As a result of this they will eventually become the individuals who might change some of the social norms that are currently exhibited. By trying to understand the attitudes in which these individuals have on women in the workplace then one can develop a better understanding of the challenges faced by women.

\section{Research Questions}

What are the opinions that young Saudi males have on the topic of gender equality within KSA?

\subsection{Research Objectives}

1) To identify the critical factors that restrict the expansion of gender equality measures in KSA

2) To try and ascertain what are the barriers that hinder women in the labour market. 
3) To gauge how men might feel about having a woman as a superior.

4) To understand what are the assumptions and beliefs that exist with issues around pregnancies, maternity leave and their role in raising children.

5) To see if there are any job roles that negates the barriers that a woman might have the work place.

\subsection{Hypothesis}

Western educated Saudi Arabian students are now more likely to accept the changes in rules that women have within the workplace due to the exposure of women in a different society.

\section{Literature Review}

In relation to this study, its importance is seen to be critical as highlighted by the way in which Metcalfe (2008), notes that there has been a drastic shift in thinking in the past 30 years or so, with relation to women in the Middle East. Metcalfe specifies further that Arab perceptions with relation to women in society can be directly attributed to the focus that has been shown with relation to global development. On the other hand Abdalla (1996) puts it down to the change in role of Arab women in society due to the increased exposure in the workplace as well as most critically the increase in education achievement. This mould is that of women who are seen as that of caregivers has been expanded on further to the point that they are seen as the weaker sex or that of individuals who should not leave the home. So in essence what was previously suggested whereby there is the presumption that men are usually seen in role of that of the breadwinner (Tary, 1983). Women ultimately are attempting to change this perception and there has been a recent significant push in whereby literature has been compiled on this issue. This ultimately has some friction due to the fact that Omair (2008) highlighted the fact that in the majority of them live in a system whereby women have less control in their lives. There is a critical need to understand whether this push exist because of Metcalfe's (2008) factors such as that of globalization, westernization and modernization or whether there exist another underlying reason as to why this might be.

One way in which this can be done is by looking at the literature that is available to see whether there is any further contributions that can be included with relation to the knowledge base that currently exist. There exists a differing element which takes into account Saudi Arabia over that of other Arab nations. This element is suggested by AlRasheed (2007) and it relates more closely to the fact that Saudi Arabia operates are very conservative view of Islam. It is important to Saudi society due to the fact that the Saudi Royal family follows this form of Islam. The Wahhabi teachings are not necessarily as prominent within other Arab nations although some neighboring countries do have a high level of Wahhabi followers. Interestingly, on a side note another prominent country within the world which has a high level of Wahhabi followers; is that of Afghanistan and significantly this form of Islam is followed by and has a great level of influence on the Afghani and Pakistani Taliban.

The history of Saudi Arabia has some significant historical implications with relation to Islam and as well as the trading civilizations that existed prior to Islam. In addition to this there also exists critical thoughts that must be drawn upon which relate to the fact that Saudi Arabia's heritage is deeply imbedded in the nomadic pasted. Saudi Arabia consists of a large number of different tribes who also follow different interpretations of Islam. Critically among the 


\section{MInstitute ${ }^{\text {Mink }}$}

Gulf nations Saudi Arabia seemed to be one of a nation that is significantly less affected by the influence of other Western civilizations (Dadfar et al., 2003).

The issue that surrounds Saudi Arabia currently can be seen by the way in which women make a miniscule amount of the total percentage of the Saudi labour force. This figure is estimated to currently stand at approximately $8.1 \%$ as of 2008 (Elamin \& Omair, 2010). The problem with this factor is that Saudi traditions have a heritage which relates to culture as well as the religious forces which suggest that women should be segregated. This can be seen throughout Saudi society such as that of malls/shopping centers which only cater for women. This allows for women to shop without the need for Hijabs, Niqabs or Burqas. Hijabs and Burqas is the common religious female clothing that is associated with Muslim women in Saudi Arabia as well as the rest of the globe. Hijabs is a clothing item that covers Muslim women hair while Burqas and Niqabs is a generally full a clothing item which covers women from head to toe and which only show the eyes of the woman.

This form of segregation can often be followed even within households with relation to relatives and guests (Guthrie, 2001). This segregation is seen throughout Saudi society but with relation to women there exist certain roles which have been actively supported in order to promote segregation (Sidani, 2005). In addition to this push there also exists a side-effect which has resulted in educated women who are unable to gain employment due to the competitive nature that exists in the limited job market within Saudi society.

In addition to these stereotypes, there can be assumptions made by organizations (managers) with reference to having an opinion as to the reasons for why women work. This ultimately leads to difficulties that women have with relation to promotion opportunities and to gain some form of representation at the top of the command chain (Kellerman \& Rhode, 2007). Even though there exist difficulties within Western organizations of women having representations of the top of the business world. When it comes to women in the Muslim world, these concerns are even more concerning due to the fact that Sidani (2005) points out in the Gender Empowerment Measure scale; The Arabic world stands in front of women's equality.

It is suggested by Elamin and Omair (2010) that one major reason for the difficulty that is exhibited within the Arab world with relation to the development of women is that, women in this region have some significant similarities. The similarities are that of religion (Islam), culture, history and language (Arabic). The only other place in which is said to be more restrictive to women is that of sub Sahara Africa (Sidani, 2005). In a study that looked at the work patterns in the Arab world, it was suggested that the most open-minded country within the GCC region was that of Kuwait which has women who accounted for approximately $25 \%$ of the workforce. This is in stark contrast to that of Saudi Arabia which is the worst performer which has approximately 10\% representation of women (Winckler, 2002).

Western philosophies of inequality in the workplace suggest that women and men should be given the same opportunities within the workplace. Furthermore, Saudi Arabia as well as nations such as the UK also have factors that women must fight against which relates to that of stereotypes. Even with the suggestions previously by Sidani (2005) which highlight some of the roles that are more accepted within Saudi Arabia, there also exist connotations which might suggest that these jobs are somewhat feminine. Ember and Ember (2004) gives this 
thinking more thought by the way they highlight that culture can impact on gender roles. The reason for this is that some cultures ultimately have differing thoughts on female roles (Rhode \& Kellerman, 2007).

The stereotypes can hinder women's opportunities with relation to progression within any organization. Stereotypes can also significantly impact on the way in which the progression in which women can progress within the work environment (Rhode \& Kellerman, 2007). Women had been battling these stereotypes for a number of years and parity with their male counterparts. Taking this into account, there has to be the understanding that a nation such as Saudi Arabia is still developing and there exist numerous stereotypes that will ultimately have to be addressed. These stereotypes ultimately stick on the front of the minds of recruiters and as such women have to deal with these hurdles and barriers when it comes to recruitment (Metcalfe, 2008). Patriarchal societies such as that of Saudi Arabia can ultimately exhibit less of a debate due to the fact that women should obey men and as such debate is somewhat restricted.

Socially there also exists another factor in which women must tackle with relation to attitudes. Social norms are exhibited within Saudi Arabia also highlight the fact that gender roles are defined and have not altered for centuries (Al-Lamki, 2007). There still exists the notion that this increased emphasis on education can have an effect on how daughters carry on these same traditions of social norms (Gallant \& Pounder, 2008).

The fact that women are trying to achieve some form of parity with their male counterparts has another major factor that must be addressed; the fact that any working woman must involve their work life balance. The fact that it is not commonplace for Saudi men to raise their children means that any woman who has children is seen to be obliged to sacrifice themselves to raising the children. This ultimately creates some problems as whereby a woman that works must deal with tradition and culture as it is presumed that there are obligate to take care of the home (Metcalfe, 2008). This notion is somewhat supported by Hijab (1988), they note that in Arab culture such as that of Saudi Arabia; women's careers should be put on the backburner when it comes to home life and especially when children are involved.

When it comes to women in management, it is noted by Fagenson (1993) is that the main barrier that exists is with relation to women in managing is that of stereotypes. It is furthermore noted that when it comes to hierarchy within organizations, women do not tend to do as well as their male counterparts and in fact it is suggested that they are given positions that have less influence and are less challenging (Omar \& Davidson, 2001). Omar and Davidson's (2001) insight are not restricted to that of Saudi Arabia but rather than that of all industrialized nations as they tend to have the same results but in different extremes. When it comes to Saudi Arabia the responsibilities of Saudi women can be significantly less critical and as such have limited power over others as well as a reduced level of responsibility (Al-Halawani, 2002)

\section{Research Approach}

This study will utilise a qualitative approach. The reason behind this thinking was due to gaining insights into different methods available in textbooks such as that of Bryman and Bell 
(2011) and Cooper and Schindler (2011). The suggestions by these academics were that by utilizing a qualitative approach, it then allowed for the possibility to gain more of an insight of the participant's opinions.

This study will have a specific segment of individuals in mind; these will be that of Saudi Arabian male students who study within the United Kingdom. Furthermore, the study will try to answer the research question, aims and hypotheses by way of conducting interviews. This will be done by utilizing traditional methods of interviewing as well as a mixed method approach of obtaining quantitative data (Brannen, 2005).

The study will furthermore take into account a wide range of secondary data in the form of books, journals and periodicals. The reason for this is that a study such as this ultimately requires some form of theoretical grounding as to the subject of gender equality. One cannot neglect the previous works that academics have done in this field. More importantly with relation to this study, by analyzing how over time the Western world has developed an altered his view on women in the workplace can only aid in giving a better understanding of the situation currently within Saudi Arabia. Although parameters differ, the core goal of gender equality within Saudi Arabia can be seen by numerous examples throughout the globe.

\section{Sample}

The study was conducted within both Saudi Arabia and the United Kingdom. It is critical to still understand that even though interviews were conducted in Saudi Arabia they only took into account the perceptions of Saudi citizens who study in the United Kingdom. The total number of participants interviewed for the purpose of the study was that of seven. The students interviewed were on different courses and furthermore there was a varying level of academic progression. The lowest level of progression in which the participants were involved with relation to academic level, was that of second year undergraduates and the highest level was that of a first-year Ph.D. student. To be more precise the study involved four undergraduate students, two Masters students and a Ph.D. student. Furthermore, all but two of the participants studied at different universities. Apart from the two students that study at the University of Huddersfield none of these participants were acquainted with each other. Moreover, as a given these participants were all male. In addition to this all the participants were between the ages of 22 and 31. It is critical to understand that this is a segment of a larger group and as such this can be highlighted by the way in which Kumar (2005) notes that in any social observational study one must take a sample of society or the target group in to account. This in essence is a sample of some individuals that can be studied. It is further noted by Kumar R (2005) that with the increase in sample size then this will increase the likelihood of validity and reliability being further promoted.

\section{Limitations}

There has to be an understanding with relation to the findings that the researcher is a Saudi national who is studying a Masters at the University of Leeds. This alone brings its own set of issues which can be namely pointed out by Bryman and Bell (2011) with reference to research bias. The fact that the researcher might empathize further with the study participants because being of similar background due to being fellow countrymen, can cause some additional research bias. 


\section{Ml Macrothink}

There exist issues that surround interpretation of data prior to the analysis. This was due to the fact that although the questions proposed to the participants was done in English, it was important to note that as with all the participants English was their second language. On some occasions clarification of the question was further requested in Arabic. The interviews took part were furthermore complicated due to the fact that they took part in Arabic and for the purpose of this study they have been translated. Translation can create its own set of problems due to the fact that meanings can differ as well as literal translations might not be as possible due to the context in which participants' opinions were articulated. Ultimately when it comes to a qualitative study there has to be an understanding that experience in conducting studies can reduce the likelihood of preconceptions being imposed upon the study participant (Bryman \& Bell, 2011).

\section{Validity and Reliability}

In order to gain credibility in any study focus must be given to validity and reliability (Baker, 2002). With relation to reliability this is somewhat restricted in this study due to the fact that it is noted that only seven participants were included in the study. In essence with this number being so low then although confidence is high reproducing the results, this cannot be taken as a given. To truly be able to confirm the reliability of the study then additional studies must be conducted to see if the results mirror up. Although the study was conducted in the form of interviews, it still was delivered by reading out predetermined questions. This brings up its own set of issues due to the fact that unlike a quantitative study a qualitative study in essence cannot be confidently analyzed mathematically.

In addition to this assertion it is important to understand that although it is suggested that qualitative studies can have its results transformed into a quantitative approach. This can be done by giving numerical associations to answers, i.e. by giving a scale of the results such as that of 1 being agreeable to 5 being disagreeable. This scale can be implemented in most qualitative studies and as such it gives the possibility of promoting reliability but this will be solely based on the subjective views of the researcher. In addition, prior to conducting this study a pilot was attempted so as to increase reliability and validity. The pilot was done in order to see whether there were any concerns so as to reduce any haziness.

\section{Ethics}

Ethically, there will be some points of concern the need to be addressed when conducting a study such as this. The fact that universities such as Leeds University, highlight the concerns in conducting social research which gives some form of interaction between its students and members of the public. Furthermore, there exist legal implications that need to be addressed. This is important no matter what form of study is conducted and when it comes to an interview method approach then there exists some significant implications that have to be addressed; these are that of the way in which studies should protect individuals so as not to cause any harm to them through any mental distress or at that even a physical one (Bryman \& Bell, 2011). For this reason it has to be significantly highlighted in ethical behavior by way of making sure that individuals' anonymity is kept safe and this should include the way in which data is stored (Cooper \& Schindler, 2011). 


\section{Results and Findings}

The results of the interviews showed that there existed some similarities in results but at the same time there existed a wide range of varying degrees of similarity. One constant that existed throughout the study was that although not all have worked with women in Saudi Arabia, they are all aware of women who work in Saudi Arabia. Significantly, all of the participants noted that when it came to women interaction in the workplace (if they had any), it tended to be segregated.

He noted that although he worked with women within the workplace. He had no real interaction with them as they only taught female students and they were not able to teach men. With relation to having female members of the family who were employed in the Saudi labour market; most of the participants said that they were aware of at least one female member who were in employment but two of the participants said that they were not aware of any who were in employment. Interestingly as a side note it was pointed out that there existed a perception over whereby the city of Jeddah in Saudi Arabia was seen to be more liberal and conservative than areas such as that of Medina and Riyadh.

When it comes to the feelings of the participants with relation to working in the same office as a woman, there exists a general agreement that apart from two participants that they would not have a problem with this. One participant in particular was adamant that he would not accommodate this possibility in any way. When it comes to the differentiation between the Saudi and non-Saudi women in the workplace, there exists a wide range of differing opinions. One specific example which highlights this clearer is the way in which is noted that in the east of Saudi Arabia, there exists groups of women who are employed in the petrochemical industry and they work side-by-side with men.

The fact that non-Saudi women can live within compounds, means that their home life is different to that of Saudi women. One participant went on to highlight that these compounds are "like Paris because people will do what they like and they can get up to naughtiness". When asked whether they had in fact ever been in these compounds? He replied "no but you hear many stories about what goes on" When questioned on the importance of religion and traditions with relation to women in the workplace. The holy Scriptures note that women and men should not be differentiated. The fact that the prophet Muhammad had daughters who worked and fought beside men is an example of this.

Thus, religion cannot be used as an excuse to keep women at home. The participants suggestion as to the reason as to why women are forced to stay at home is that of traditions and customs and not religion. This fact is not without its problems as some of the participants suggested that the way in which religion becomes a problem relates to that of segregating the men from the women in the workplace. There is a belief that women can perform as well as men in certain roles but overall there seems to be a general consensus that women can be affected due to physiology and psychology. There exist a majority of participants who bring up the issue of child rearing prior to even being asked to do so. This became sometimes problematic within the study as there are constant links to this.

As and whereas Western countries have women who choose not to have children and instead focus on their careers (Shaw, 2010). This concept is still somewhat foreign to Saudi Arabia. 


\section{Mll Macrothink}

One can say that the only way in which this is exhibited as a thought exists with that of women who are unable to bear children. It was seen that three participants of the study suggested that in fact women in some cases can be more competent due to their intellectual ability. One example of this was a Huddersfield student who is doing accounting, suggested that he believed that women were far more superior to men when it came to accountancy and mathematics.

All the participants even the strongest participants against women's equality in employment highlight that their perceptions have even been somewhat or drastically altered due to studying abroad. Majority highlight the fact that they had been able to interact with women in the workplace be it lecturers or colleagues that have made them change their opinions. This brings great promise to the battle for women's equality in Saudi Arabia. The reason for this is that over time there seems to be a perception in which people's beliefs are changing due to western exposure.

Furthermore, these perceptions and opinions seem to be somewhat newly developed. Even with the people who felt that they believe that women's equality should be improved, stated "before I left Saudi Arabia I didn't believe that women and men could work together without any problems". It is just a small glimpse into some of the thoughts that can be seen with relation to the two genders working together. Furthermore, the differences in perceptions and opinions were somewhat random compared to which geographical regions they came from or whether they were from a rural or metropolitan area.

When it came to see whether individuals would approve of having a woman has their direct line manager. This brought up some strong feelings. In fact, one individual said that they would not choose to work with women as they "cannot control their feelings". Some individuals believe that they would not have any issue with this but they understood that a majority of their colleagues might do. This resulted in a varied insight as to the participant's position as they all had significantly varying opinions. When probed further into their answers, one individual said that even if his colleagues were against a woman line manager.

The question as to why some policies that are introduced in other countries such as the United Kingdom are not as wide reaching as in Saudi Arabia. It was suggested one must have an understanding that culture and mentality had a major impact on this. Furthermore, there are exhibited individuals who suggested that it could be due to financial implications as this might result in even more money being spent on drivers for women. In addition, three of the seven participants stated that the reason for this is that the ruler of Saudi Arabia almost always tends to be old and as such legislative changes take time.

In addition some blame is also placed upon the Saudi religious advisers but not religion itself. The reason for this is that it is suggested that these religious advisers also tend to be elderly and include their perjuries when relating the holy script to modern day life. Furthermore, education also has an impact as there exist a rural/tribal mentality which can impact on Saudi Arabia and any legislation must try to address them. One individual believes that the reason for this is that the Royal family did not want to go against these powerful religious advisers. These feelings can be somewhat highlighted by the way in which Al-Rasheed $(2007 ; 2010)$ notes there exists a feeling that it is one of the duties of the Saudi Royal family to be a protector of Islamic morals within the kingdom. 


\section{Macrothink}

Significantly a majority of the participants suggest that society forces are the biggest reason for the barrier exists for women in the labour market. Although, the literature analyze previously suggest that women believe that patriarchy is the biggest barrier. The male participants generally suggest that this is due to culture and tradition. When it came to understanding how Saudi men felt about pregnant workers. The opinions of these were wide and varied from individuals who felt that during any part of the pregnancy, women should not be working. Some felt that they can operate until the eighth months of pregnancy.

When questioned about paternity leave. Approximately half of the participants suggested that mention in fact receive maternity leave and that it was great to bond with the child. It was felt that this was more likely with relation to the first child born but subsequent children were not as important to gain a bond with. When it comes to changing perceptions of women in the workplace, when asked who was should be trying to achieve this, whether it was men or women. There exist a divide of whereby almost half the participants believe that it is up to women to try and get an equal footing with relation to equality in the workplace. One individual suggests that "if you want something then you must take it". On the other hand one individual suggested that women do not have enough sway in Saudi culture to implement change.

When it came to raise a question about the Guardian system this caused a lot of confusion. The fact that some individuals noted that employers can be affected by the Guardian system, they also felt that husbands and fathers have a right to protect their women. This question ultimately gave numerous different opinions. It shows that Saudi Arabia is at a crossroad with relation to women's equality rights and the rights of their guardians. The problem that is seen with relation to the questions raised shows how the influence of society makes these issues somewhat problematic to resolve. Studying in a different country has shown that women have the right to come and go as they choose but this is again a foreign concept in a majority of cases in Saudi Arabia.

When asked about which roles would be suitable for women there existed a belief that although all role should be open to women in theory this is not possible practically. It is suggested that women have the ability to be introduced into more roles rather that of the ones highlighted within the literature review. Roles which are gender specific cause problems economically as they are a higher level of saturation in the job markets. The problem is that not all roles are accessible to women as although their exist women that work in the petrochemical industry.

\section{Discussion}

The fact that it is suggested that Saudi Arabia has a high level of unemployment, means that in theory there exists some underlying friction that can be examined further. Since the typical cultural norms is that men on the breadwinners. There exists a small perception that unemployment has another dimension with relation to gender equality. The reason for this suggestion is that two individuals somewhat touched upon the subject but one was quite insistent that unemployment is one reason for a barrier for women having access to the labour market. Nations with these high unemployment rates can have an increasing following of individuals who believe that the natives should have preferential treatment over other segments of the labour force. 


\section{$\triangle$ Macrothink}

Another point was brought up was that even if women and men have the ability to compete in the same jobs market. Men will be ultimately more likely to succeed in performing better due to the fact that training and development is more easily available to them. They noted that there exist other factors that should be taken into account as with the forces that exist within Saudi Arabia. Women do not have the same freedom to travel back and forth. This again highlights how there exists forces in play with relation to the development of the female labour market participation. Factors such as these go against some of the traditions that exist within Saudi Arabia.

The fact that if a husband or their guardian does not give permission for a woman to go to a training opportunity, then the employer is also affected. These hindrances to women's opportunities are not isolated to this example along. Other points that were raised was the fact that women are not able to drive means that they can be limited in the workplace with relation to the type of jobs they can have. Similarly, the fact that drivers are required means they might be additional costs to business. It is furthermore suggested that the impact that exists with these measures means that even simple actions such as that of end of year or other staff events almost always not include female workers.

The results show that women have had to deal with a lot of stereotypes that exist within Saudi society. Furthermore there exists differing types of stereotypes that exist. The problem with relation to tackling this issue can be seen by the way in which people's opinions vary drastically. Although there exists an underlying supporting arguments such as the fact that culture and tradition play more of an impact than religion; as the forces of a patriarchal society more powerful than one might assume.

\section{Conclusion}

With relation to the literature that exists on the subject. There has to be an understanding that although attention has been drawn upon the issue of gender inequality in the Middle East. There exists less of an understanding of how this issue impacts within KSA's borders. It is vital to understand that some of the perceptions that exist about Saudi Arabia can be suggested to be valid but somewhat misplaced. The literature shows that religion is not necessarily the main factor that restricts the development of gender equality in Saudi Arabia. In truth, other factors such as that of culture and tradition impacts this issue more.

Specifically, this relates to the patriarchal society that exists within Arab countries as well as in particular with that of Saudi Arabia. The system that exists within Saudi Arabia with relation to the Guardian system causes some significant complications and external forces that affect gender equality. Although stereotypes in the workplace can be seen throughout the globe, there seems to be more of an overt form of stereotyping with relation to Saudi women in the workplace. For example it is suggested that in the UK this form of discrimination and is somewhat less obvious. In addition to this the same students will have difficulty in seeking employment in KSA. The reason for this is that although unemployment is high within Saudi Arabia only $8.1 \%$ of the labour force is that of women. The fact that women are not allowed to drive cars might impact on their work life.

In addition the data collated with relation to the interviews conducted. It can be seen that there is a gradual shift towards positive perceptions of women in the workplace. All the 
participants interviewed showed that there was a shift in perception of working alongside women. There exists a feeling that over time Saudi Arabia's policies and views of women in the workplace will alter. This contact can be seen throughout Saudi society with relation to the international business that it conducts as well as former students who have studied in different countries. One factor that is prominent with relation to Saudi culture relates to seeing women only as caregivers. This is deeply ingrained in society and it can be seen by a majority of individuals who support the notion women in the workplace.

At the end of the day with relation to the hypothesis of this paper, it can be suggested that it has been proved to be a valid observation. It is felt that the reason for this is that individuals cannot ignore the environment that they interact with. As such all Saudi students will be in some way affected and as such they will alter their preconceptions. Saudi Arabia and the UK societies vastly differ in the way in which women are viewed in the workplace.

\section{Recommendations}

The study was significantly limited in its insight due to the experience of the researcher as well as the restrictive nature of the word count. It is felt that although the hypothesis was felt to be validated. One recommendation that can be proposed relate to the way in which although not truly intended, it is suggested that there can exist regional variations in perceptions. The reason for this suggestion is that there was some significant mention of Jeddah being significantly more liberal than that of other regions around the country. Furthermore, in the east of Saudi Arabia there exists a perception that women are less restricted to work in somewhat more stereotypical male job roles. This relates specifically to that of women being employed within the petrochemical industry. Any such study that tries to look into this will ultimately have to be significant in size. This is due to seeing whether there does in fact exist certain industries or different geographical regions that are more or less accepting of women in the workplace.

When it comes to the feelings of which might exist with relation to Saudi men working alongside women, there exist some friction but this is significantly less than that of having a Saudi woman as a manager. It is presumed by the data that Saudi men will have more friction with the notion of having a woman as a line manager. Ultimately, since it is not a societal norm there exists a feeling this will ultimately lead to men being emasculated. It is felt that the only way in which gender equality can truly be tackled in Saudi Arabia, is by firstly employing women in the workplace rather than that of causing untold friction by having women in senior roles.

\section{References}

Abdalla, I. (1996). Attitudes towards women in the Arabian Gulf region. Women in Management Review, 11(1), 29-39. https://doi.org/10.1108/09649429610109271

Al-Lamki, A. (2007). Feminizing leadership in Arab societies: the perspectives of Omani female leaders. Women in Management Review, 22(1), 49-67. https://doi.org/10.1108/09649420710726229

Al-Halawani, I. (2002). The obstacles that stand in the way of working women and impede the progress of success. Arab Journal of Management, 22(2), 61-120.

Al-Rasheed, M. (2007). Contesting the Saudi State: Islamic voices from a new generation. 
Cambridge: Cambridge University press. https://doi.org/10.1017/CBO9780511993510

Al-Rasheed, M. (2010). A History of Saudi Arabia. Cambridge: Cambridge University press.

Baker M. J. (2002). Sampling. The journal of The Marketing, 3, 103-120. https://doi.org/10.1362/146934702321477253

Brannen, J. 2005. Mixing methods: The entry of qualitative and quantitative approaches into the research process. International Journal of Social Research Methodology, 8(3), 173-184. https://doi.org/10.1080/13645570500154642

Bryman, A., \& Bell, E. (2011). Business research methods. New York: Oxford University Press.

Cooper, D. R., \& Schindler, P. S. (2011). Business Research Methods. Singapore: McGraw-Hill/Irwin.

Dadfar, A., Norberg, R., Helander, E., Schuster, S., \& Zufferey, A. (2003). Intercultural Aspects of Doing Business with Saudi Arabia. Linkoping: Linkoping University.

Elamin, A. M., \& Omair, K. (2010). Males' attitudes towards working females in Saudi Arabia. Personnel Review, 39(6), 746-766. https://doi.org/10.1108/00483481011075594

Ember, C. R., \& Ember, M. (2004). Encyclopedia of Sex and Gender: Men and Women in the World's Cultures. Volume I: Topics and Cultures A-K. New York: Kluwer Academic/Plenum Publishers. https://doi.org/10.1007/0-387-29907-6

Fagenson, E. (1993). Women in Management: Trends, Issues, and Challenges in Managerial Diversity. Thousand Oaks: Sage.

Gallant, M., \& Pounder, J. S. (2008). The employment of female nationals in the United Arab Emirates (UAE): an analysis of opportunities and barriers. Education, Business and Society: Contemporary Middle Eastern Issues, 1(1), 26-33. https://doi.org/10.1108/17537980810 861493

Guthrie, S. (2001). Arab Women in the Middle Ages: Private Lives and Public Roles. London: Saqi Books.

Hijab, N. (1988). Womanpower: The Arab Debate on Women at Work. Cambridge: Cambridge University Press. https://doi.org/10.1017/CBO9780511628115

Kellerman, B., \& Rhode, D. L. (2007). Women and Leadership: The State of Play and Strategies for Change. New York: John Wiley \& Sons.

Kumar, R. (2005). Research Methodology: a step-by-step guide for beginners. London: Prentice Hall. https://doi.org/10.3758/BF03192704

Metcalfe, B. D. (2008). Women, management and globalization in the Middle East. Journal of Business Ethics, 83(1), 85-100. https://doi.org/10.1007/s10551-007-9654-3

Omair, K. (2008). Women in management in the Arab context. Education, Business and Society: Contemporary Middle Eastern Issues, 1(2), 107-123. https://doi.org/10.1108/ 17537980810890293

Omar, A., \& Davidson. M. J. (2001). Woman in management: A comparative crosscultural overview. Cross Cultural Management, 8(3/4), 35-67. https://doi.org/10.1108/1352760 0110797272

Rhode, D. L., \& Kellerman, B. (2007). Women and Leadership: The State of Play and 


\section{Macrothink}

Strategies for Change. New York: John Wiley and Sons.

Roulston, K. (2010). Considering quality in qualitative interviewing. Qualitative Research, 10(2), 199-228. https://doi.org/10.1177/1468794109356739

Schreiber, P. J. (1998). Women's career development patterns. New Directions for Adult and Continuing Education, 80, 5-13. https://doi.org/10.1002/ace.8001

Shaw, R. L. (2010). Women's experiential journey toward voluntary childlessness: An interpretative phenomenological analysis, Journal of Community \& Applied Social Psychology, 21(2), 151-163. https://doi.org/10.1002/casp.1072

Sidani, Y. (2005). Women, work, and Islam in Arab societies. Women in Management Review, 20(7), 498-512. https://doi.org/10.1108/09649420510624738

Tary, L. (1983). Women and the new unemployment. Humboldt Journal of Social Relations, $10,47-60$.

Thomas, T. (2012). Saudi extends scholarship scheme to 2020. Retrieved from http://thepienews.com/news/saudi-extends-scholarships-for-2020

Walby, S. (2004). The European Union and gender equality: emergent varieties of gender regime. Social politics, 11(1), 4-29. https://doi.org/10.1093/sp/jxh024

Winckler, O. (2002). The demographic dilemma of the Arab World: the employment aspect, Journal of Contemporary History, 37(4), 617-636. https://doi.org/10.1177/002200940203 70040701

\section{Copyright Disclaimer}

Copyright for this article is retained by the author(s), with first publication rights granted to the journal.

This is an open-access article distributed under the terms and conditions of the Creative Commons Attribution license (http://creativecommons.org/licenses/by/3.0/). 